\title{
Diversity in a Global Era: The context and consequences of differences
}

\author{
Anthony J. Marsella* \\ Department of Psychology, University of Hawaii, Honolulu, Hawaii, USA
}

Global challenges (e.g., hegemonic globalization, demographic shifts, poverty/famine, conflicts and wars, and environmental disasters) are bringing diverse populations into contact under conditions of rapid socio-technical changes, social upheaval, conflict, competition, uncertainty, and anger and resentment. These complex circumstances of interpersonal and national contact are associated with widespread psycho-social and socio-political problems. Powerful global efforts to reduce diversity conflicts by the hegemonic imposition of Western economic, political, and cultural systems is not a solution to the emerging diversity conflict issues. Rather, the "global monoculturalism" being promoted represents an exacerbation of the problem as evidenced by the growing radicalization of individuals, groups, and nations seeking to resist the homogenization pressures. This paper offers a series of recommendations for individual and collective solutions that may serve to promote and to sustain both diversity and solidarity via both policies and actions. The recommendations include world citizenship, global leadership, diversity education and training, positive attitudinal shifts, universal human rights, and the development of the full-functioning global citizen. Nobel Laureate Octavio Paz has noted: "Life is diversity, death is uniformity.... Every view of the world that becomes extinct, every culture that disappears, diminishes a possibility of life". Clearly, diversity and unity are not opposites to be pursued independently, but rather manifestations of the same principle on which our universe was born and functions - fission and fusion - separation and connection. Diversity is life. Life is diversity.

Keywords: diversity; global; hegemonic globalization; monoculturalism; human rights; ecology of conflict

\section{Introduction}

Shall we write about the things

Not be spoken of?

Shall we divulge the things

Not to be divulged?

Shall we pronounce the things

Not to be pronounced?

Julian the Apostate (332-363 CE)

Hymn to the Mother of the Gods

*Email: marsella@hawaii.edu 
As we face the perils and possibilities of our present life in a global era, we might draw some comfort from the fact that each era has been filled with social and political turbulence, instability, and chaos. Yet, I think it would be unwise for us to see historical parallels as sources of consolation because our current era differs so dramatically. Today, we live as individuals, societies, and nations under conditions of near total interdependency exposing us to risks and vulnerabilities of new proportion and consequence. There is a new global ecology of challenges, consequences, and potential solutions that requires bold and imaginative courses of thought and action. In this global era, diversity looms as a serious challenge. In this article, I wish to speak about diversity in a broad way - what it is, why it is essential, and what we must do to sustain it in the face of pressing efforts to homogenize us as humans beings into a vast consumer culture under the control of a limited few for reasons that stand in opposition to universal human rights and human dignities.

\section{Diversity in a Global Era}

A decade ago, as the realities of the emerging global community began to become apparent and as the term "globalization" was gaining popularity, I wrote the following:

Human survival and well being is now embedded in a complex and interdependent global web of economic, political, social, technical, and environmental events, forces, and changes. The scale, complexity, and consequences of these events, forces, and changes constitute an important challenge to our individual and collective well being by confronting us with an array of complex, conflicting, and confusing demands and/or opportunities. Our response to this challenge - as individuals and as societies [and as nations] - will shape the nature, quality, meaning, and [security] of our lives in the coming century. (Marsella, 1998, p. 289)

\section{Global challenges}

I feel these words and their prescient admonition remain applicable today. For what has occurred in the last few decades is a compression of forces, events, and changes within a brief period of time that has overwhelmed our understanding and capacity to respond in a positive way. I write here not only of international terrorism, the onset and continuation of two tragic and immoral high intensity wars that have divided the world's nations and religions, nor the scores of low intensity conflicts resulting in genocidal and ethnic cleansing, but also the massive levels of poverty, famine, migration waves, demographic shifts, and environmental disasters that are bringing people from diverse races, cultures, religions, and histories into contact with one another - into contact with our diversities - often under conditions of harsh asymmetries in power and control that foster humiliation, distrust, anger, violence, and distrust, and that in their extremes, foster disorder and disease.

Jay Lifton, an articulate and perceptive commentator on the social character of our times, stated it so well. He used the term "The Protean Self" - meaning varied and many faceted self - to describe the situation we are experiencing:

We feel ourselves buffeted by unmanageable historical forces and social uncertainties.... Enduring moral convictions, clear principles of action and 
behavior: We believe these must exist, but where? Whether dealing with world problems or child rearing, our behavior tends to be ad hoc, more or less decided upon as we go along. We are beset by a contradiction: Schooled in the virtues of constancy and stability - whether as individuals, groups, or nations - our world and our lives seem inconstant and utterly unpredictable. We readily come to view ourselves as unsteady, neurotic, or worse (Lifton, 1993)

\section{Diversity}

\section{Diversity is source of conflict/diversity is source of survival}

On this, the dawning years of a new century and millennia, two indisputable facts confront us! First, the majority of instances of local, national, regional, and global problems can be traced to conflicts involving cultural and racial diversity. Second, the greatest resource for ensuring the survival and growth of the human race is cultural diversity. While the first fact may seem more apparent than the second, both are nonetheless true, and both are nonetheless critical for national and international stability. Thus, we are faced with a paradox: A single characteristic of human life diversity - looms as both the principal source of tensions and conflict and as the principal resource for the survival and growth of the human species (Marsella, 1994b).

\section{Diversity elicits arousal, alarm, and sometimes aggression}

Diversity is about differences, and according to evolutionary psychologists, the human mind does not lend itself easily to negotiating differences. Indeed, the human brain's response to differences is typically arousal, alarm, and sometimes attack, until such time as the differences are processed by exposure, reason, or mastery. Figure 1 captures some of the many and complex interactions between social diversity markers and different settings that have consequences for our individual and collective health and well being.

But it is more than the differences that are the source of problems, it is the perceptions under which diversity encounters are occurring. Some of the most problematic perceptions include the following:

- Perception of danger to survival, identity, well being

- Perception of "Other" as evil, dangerous, threatening

- Perception of the situation as unjust, unequal, unfair, humiliating, punishing

- Perception of competition for limited resources

- Perception of self as self-righteous, moral, justified, and "good" by virtue of religion, history, identity

- Perception that normal pathways for resolution may no longer be available accessible, and/or acceptable

- Availability of military or police strength and other means to engage in violence and war

- Availability of media for hyping positions through lies, deception, and delusions

- Availability of "people" willing to fan conflicts for personal, economic, and political gain. 


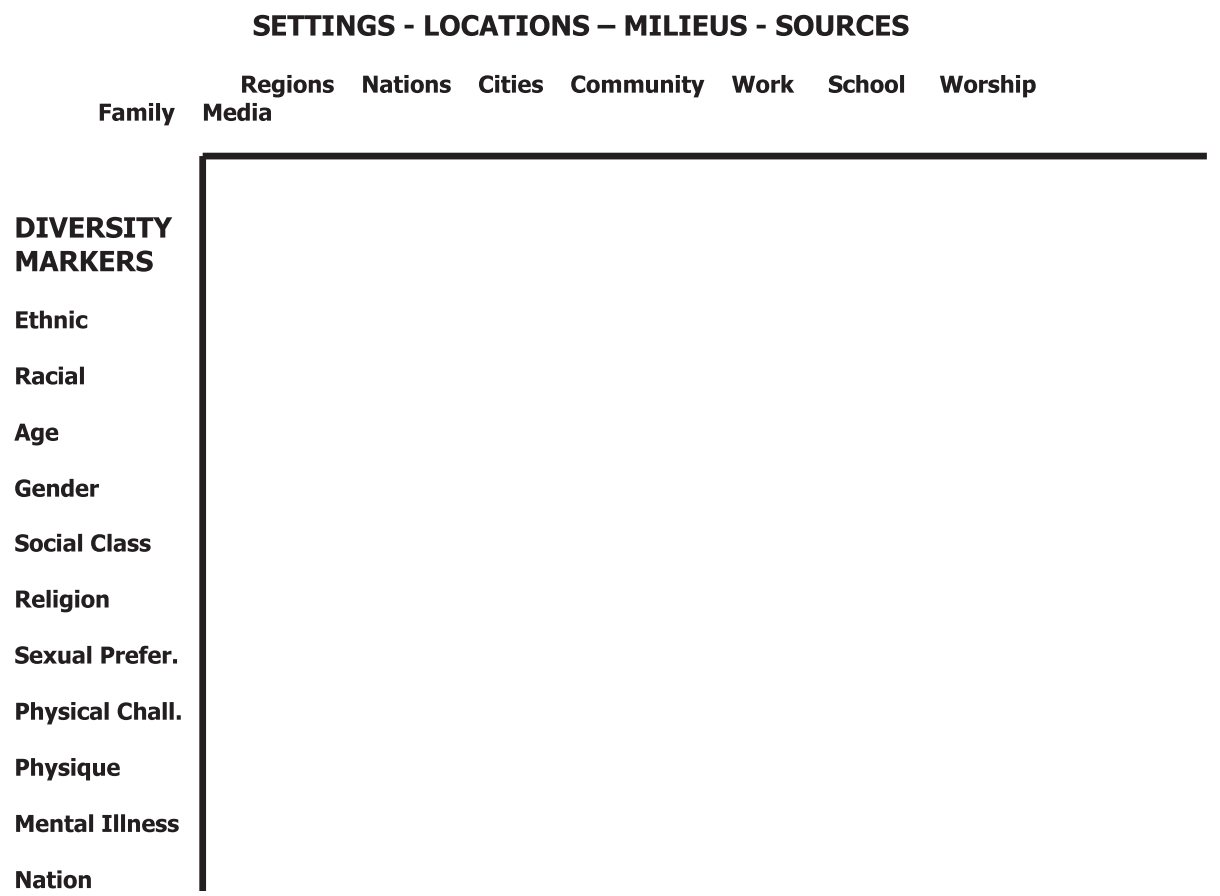

Figure 1. The social diversity ecology matrix.

Note: In each of these ecologies, encounters occur under different conditions of acceptability. Sometimes there is conflict and sometimes there is harmony. More needs to be done to examine diversity ecology encounters to help determine the sources for promoting positive relations.

\section{Ethnocultural diversity}

The bottom line is this! In this global era, cultural competencies are required for all. Cultural diversities must not be denied nor ignored. Rather they must be seen as topics requiring understanding, sensitivity, and appreciation. A first step for this is a better understanding of the concept of culture itself since it is clear that culture is a powerful determinant of normal and abnormal human behavior. Briefly, culture can be defined as "... shared learned behavior and meanings that are socially transferred in various life-activity settings for purposes of individual and collective adjustment and adaptation". Cultures are represented and experienced externally (i.e., artifacts, roles, institutions, social structures) and internally (i.e., values, beliefs, attitudes, axioms, orientations, epistemologies, consciousness levels, perceptions, expectations, personhood). Culture is outside, but it is also a matter of heart, mind, and body. A diversity encounter between people, families, societies, and nations means that different realities must be negotiated.

As Figure 2 indicates, the global context of our lives is presenting us challenges that are shaping a broad spectrum of psychosocial and socio-political problems. I wish to discuss five global challenges that are particular sources of problems 


\section{Global Challenges}

(e.g., Hegemonic Globalization, Demographics, Poverty/Famine, War/Conflict, Environmental Disasters)

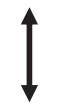

\section{Negotiate Diversity}

(Differences in World View, Values, Ways of Knowing, Assumptions, Reality Construction, Morality)

(Rapid Change, Uncertainty, Confusion, Frustration,
Competition, Social Upheaval, Anger)

Figure 2. The complex global ecology diversity.

because they bring diverse people together under problematic circumstances. These include: (i) The reality and perils of hegemonic globalization, (ii) emerging demographic realities, (iii) global poverty and famine, (iv) environmental crises, and (v) current wars and conflicts. In my opinion, mental health systems must reduce their ethnocentricity and redesign their services to respond to the new spectrum of challenges and emerging psycho-social and socio-political dysfunctions and disorders.

\section{The complex global ecology of diversity}

\section{Challenges and facts}

\section{(1) Hegemonic globalization}

The world in which we live today is a global community. Our lives, our hopes, our aspirations, our very survival are now intertwined and interdependent. This is true 
for individuals, societies, organizations, and nations. We may pretend that this is not the case - we may even wish that this was not the case - but the reality is that few things are now either local in origin and/or consequence. This simple fact - this reality - has changed all of our lives by revising our past, complicating our present, and confusing our future.

The issue is not globalization, but hegemonic globalization (Marsella, 2005). I use the term "hegemonic" because of globalization's control and dominance by powerful individual, national, and multinational corporations whose policies, plans, and actions are threatening cultural and biological diversity and promoting the rise of global monoculturalism. Hegemonic globalization permits a limited number of powerful nations to impose their economic, political, and cultural interests and agendas on others without the opportunity to negotiate the circumstances nor the consequences of these efforts. What these nations and corporations have learned is that it does not matter what the people want, simply control the nation's political and economic leaders and you can do what you want.

A serious concern of "hegemonic" globalization is the imposition of values associated with North American (i.e., United States) popular culture, including individualism, materialism, competition, hedonism, rapid change ("progress"), profit, greed, commodification, consumerism, reductionism, celebritization, privatization, and English-language preference. These values carry with them ways of life that are alien and offensive to many people throughout the world, including many Western residents. However, they are powerful values, generated and sustained by institutions and organizations with self-serving agendas. Of special concern is the fact that American popular culture values are becoming the preferences of youth around the world Chomsky (2003). People around the world are resisting this imposition - this hegemony - and are responding to it with radicalized feminist, nationalist, sub-nationalist, religious, environmental, and local protests.

At the heart of hegemonic globalization is the ubiquitous - and deservedly maligned - corporation. Bakan (2004) has written one of the most penetrating analyses of the corporation and the dangers inherent in its structure, function, and legal status. For Bakan, the corporation is a pathological force across the world, not only a major source of problems. Maser (2004) notes that the corporation grew out of the British Crown's need for an entity that would enable it to exploit its colonies (e.g., India, Africa) without having to assume any moral responsibility for their actions. Maser points out that the corporation is an immoral entity. He writes:

This conscious separation of personal responsibility from the act of looting is not surprising because "looting" is, theoretically as least, considered immoral in Christian circles. The corporation is thus a "legal fiction", that lets the investors who own the business avoid personal responsibility whenever the business dealings are unethical or even blatantly illegal, despite the fact that such unscrupulous behavior profits them enormously.

A corporation, after all, has but one purpose - to make money for the owners. Economist Milton Friedman gave voice to this pinhole vision when he answered his own rhetorical question: "So the question is, do corporate executives, provided they stay within the law, have responsibilities in their business activities other than to make as much money for their stockholders as possible?" And my answer to that is, "no they do not". In fact, the "corporate system", say analysts, "has no room for beneficence 
toward employees, communities, or the environment", a notion endlessly demonstrated on a daily global scale. (Maser, 2004, 2007)

Maser's words are illuminating but not surprising. We have all witnessed the widespread consequences of corporate irresponsibility, fraud, deceit, and criminal activity. Untold millions have died or been injured in the corporation's pursuit of power and profit. What is critical in our global era is that we are using the corporation as the spearhead of "hegemonic" globalization. This cannot continue without eventual violence. In what some may consider an extreme position, Douglas Porch, a British historian, draws an interesting analogy to past imperialistic eras. In his volume, Wars of Empire, he states:

Through imperialism, poverty would be transformed into prosperity, the savage would be saved, superstition would vanish into enlightenment, and order would be imposed where once only turmoil and barbarism reigned." The peace operations and humanitarian interventions of the late 20th and 21st centuries may be seen as a revival, albeit in less violent form, of yesterday's "savage wars of peace." The ultimate goal was similar: fling open markets to the global economy, bring government to the hitherto ungovernable, end tribal conflict and ethnic cleansing, and recruit converts for the Western way of life. (Porch, 2001, p. 16)

\section{(2) Demographic events and forces}

Demography. Demographic changes that are occurring are shaping a new global profile within and among nations. Consider these demographic realities: Five of six people in the world are non-Caucasian. The total Caucasian populations of the United Kingdom, Ireland, Germany, all the Scandinavian countries, Holland, Belgium, and Luxembourg is less than the population of Indonesia. Ninety percent of the world's population growth is occurring in developing nations. The birthrates of most Northern European countries are so low that populations are not renewing themselves. Italy is a case in point since birthrates are estimated to be around 1.3.

North American population growth would be minimal were it not for legal and illegal immigration and the high birth rates among non-white minorities. In the United States, Latino, Black, American, American Indian, Asian-American Indian, and Native Hawaiian and Pacific Islander populations will exceed Whites by 2042. The source of this projected change is higher birthrates among non-whites, increased foreign immigration, and higher mortality rates among older White populations. New population estimates for the USA are 400 million by 2039 and 439 million by 2050 . The non-white minorities will “... constitute a majority of children under 18 by 2023" (Roberts, 2008, p. 1).

The world's population is currently 6.4 billion and it is estimated to rise to more than 9 billion within the next three decades. Nine billion people, each seeking to survive, each consuming more resources, each witnessing or experiencing the "versus" mentality of our times, each struggling to make sure that they do not fall victim to poverty. And what is especially of note is that it is not population growth itself, but the disproportionate consumption of resources among developed countries and the emerging powers of China and India.

Refugees and IDPS. There are more than 40 million refuges and internally displaced people in the world - people uprooted from their homes, lands, and ways of life. 
The war in Iraq has led to four million refugees. As far as I can determine, the United States has granted asylum to very few compared to other nations; this is certainly an index of compassionate conservatism. Government agencies and NGOs are exhausting their resources for coping with the refugee and IDP problems generated by war and natural disasters. Deaths in the Congo, Darfur, and the Middle East are in the millions.

Migration. A related demographic issue is migration. Migrants from various cultures are becoming one of the most powerful sources for social change in countries around the world. But what is especially notable is the way that many migrants from developing nations are mistreated, abused, and blamed for a score of social problems. We dehumanize them - we speak of them as threats to our survival and social formation, we deny that universal human rights, we exploit their labor but give them little dignity in return. When it comes to migrants, xenophobia and cries for law and order rise to a new crescendo. Build walls - concrete walls and psychological walls - walls like Germany did in WW II in Warsaw and the USSR did in post-war Europe - walls like the US is doing on its Mexico border and Israel in Jerusalem. Anti-migrant sentiment is widespread across circles in Europe, North America, and in Australia. We know the phrases: "They are different!", "They are dangerous", "Send them back". We avoid discussion and debate regarding the circumstances that generate migration - the global structural injustices and inequities.

\section{(3) Poverty, famine, employment}

Poverty. More than $20 \%$ of the world's population lives in absolute poverty. This means this population has no predictable and consistent access to shelter, water, and food. Sub-Saharan Africa is a particularly disastrous area. Poverty breeds hopelessness and hopelessness leads to desperation and desperation leads to violence. Poverty and famine are so widespread that even in the "wealthy" United States, 12 million families, or $11.2 \%$ of all US households, have insufficient food for their members, and $17.6 \%$ of children live beneath the poverty line. This in a nation that willingly spends a minimum of 200 billion dollars a year for illegal and immoral wars in Iraq and Afghanistan and for supporting a military-industrial complex filled with corruption (Pilisuk \& Rountree, 2008). This in a nation that paid the retired President of Exxon a bonus of 400 million dollars upon his retirement. This in a nation that paid a star baseball player 25 million dollars a year. Let me remind you at this point that poverty is the single greatest predictor of disease and the single greatest impediment to well being.

Famine. A recent report on the global food crisis noted that the United Nations does not have sufficient funds to stem the famine crisis: Borger (2008) writes:

With voluntary contributions from the world's wealthy nations, the WFP feeds 73 million people in 78 countries, less than a 10th of the total number of the world's undernourished. Its agreed budget for 2008 was $\$ 2.9 \mathrm{bn}$ ( $£ 1.5 \mathrm{bn})$. But with annual food price increases around the world of up to $40 \%$ and dramatic hikes in fuel costs, that budget is no longer enough even to maintain current food deliveries. (Borger, 2008, p. 1) 
The situation has reached international crisis proportions and violence is emerging as a response to the indignities of food deprivation and denial. The developed countries with their emphasis on negotiating commodities for profit must grasp that human right and need for food. Profit must not be permitted to create famine.

Employment and unemployment. Today, rates of unemployment and underemployment in many nations exceed $50 \%$. If there is no work, there is no money. What are people to do as they watch their family members die. How does one endure the humiliation? In many nations, the youth become disenchanted and radicalization occurs. In time, radicalization can assume terroristic proportions with high levels of anger and hate directed toward those nations seen to be the source of the problem. The changes in the conventional work situation in Western nations is now being altered by profound shifts that include: automatization, outsourcing, downsizing, temp hires, perma-temps, increased absenteeism, poor job performance, union busting, workplace violence and vandalism. Workers now know they are commodities to be manipulated for the "bottom line".

Lastly, the costs of poverty are so much greater than the costs to fix it! A recent report at the American Association for the Advancement for Science meetings reported that neuroscientists have found "many children growing up in very poor families with low social status experience unhealthy levels of stress hormones, which impair their neural development". The effect is to permanently impair language development and memory and hence the ability to escape poverty. This led Paul Krugman, a reporter, to conclude that "... poverty in early childhood poisons the brain". By this Krugman means that the life stresses associated with poverty (e.g., nutritional deprivation, stress hormonal surges) constitute an enduring developmental burden (Krugman, 2008). And to this must be added the serious levels of nutritional deficiency, disease exposure, homelessness, and abandonment that is present around the world. Protein deprivation in the first two years of life results in permanent brain and neurological damage.

\section{(4) Conflict, violence, and war}

It is estimated that there are more than 30 wars and low-intensity conflicts occurring in the world today. While the wars in Iraq and Afghanistan capture headlines, we must not forget the struggles in South and Southeast Asia (e.g., Burma, Sri Lanka, Bangladesh, Pakistan, Philippines, Kashmir), South America (e.g., Colombia, Peru), Africa (e.g., Algeria, Chad, Congo, Eritrea/Ethiopia, Kenya, Nigeria, Somalia, Sudan), Europe (e.g., Chechnya, Kosovo, Basque/Spain, Northern Ireland) East Asia (e.g., Tibet), and the Middle East (e.g., Palestine/Israel, Lebanon, Algeria, Turkey). And while war may be an inappropriate way to characterize it, we should not forget the oppression, imprisonment, abuse, and abandonment of American Blacks, American Indians, and Hispanics in the United States, Aboriginals in Australia, Bahais in Iran, and Blacks in South Africa. In all these instances, racial, ethnic, and religious diversity confounded with marginalization, economic exploitation, and corrupt national leaders lurk as causes.

At the heart of each conflict and war are the usual well known and accepted reasons. But the economic, political, and moral consequences continue to elude our discussion and debate. For example, the United States spends more on its national 
defense and military than the rest of the world combined. Its total costs - overt and covert - may well approach a trillion dollars annually. And it must be noted that the USA is one of the leading exporters of military arms to other nations - it is in the business of making war (Pilisuk, 2007) via the vast military-industrial-legislative complex. At what point have our fears of "other" become self-inflicted burdens for our daily lives? Are our fears justified or does their promotion and encouragement serve the needs of those in political and commercial power who are seeking greater control and dominance of our lives?

\section{(5) Environmental disasters: Man made and natural}

The past decade, more than any other period in our history, has brought home the terrible human, social, and economic consequences of natural and human-made disasters. Media images and headlines of fires, mudslides, hurricanes, floods, and terrorism became part of daily life across the world. No sooner did one disaster pass than another occurred, each time reminding us of the horrors of human suffering and victimization that are part of natural and human-made disasters. Table 1 (from Marsella, Johnson, Watson, \& Gryczynski, 2008, p. 7) provides a list of the different types of natural and man-made disasters the world has witnessed in recent years.

This is especially true in the case of developing nations when local aid and resources are typically limited and international assistance is required. Much as an ethnic culture has its reality assumptions, values, leaders, social structure, communication patterns, and ways of knowing and adjusting to meet the needs and challenges of life, a disaster generates a similar culture milieu and context, but this time the situation is increasingly complex because of the addition of outsiders (i.e., other world views) and the pressing burden of the disaster.

Disasters also have complex global political implications for individuals, societies, and nations because of the problematic cultural encounters that occur when victims and service providers from contrasting cultural traditions must work with one another. Michael Wessells, one of the most active and knowledgeable

Table 1. Disaster types.

\begin{tabular}{|c|c|}
\hline Natural disasters & Human-caused disasters \\
\hline Avalanches & Accidents in communities or work sites Bombs \\
\hline $\begin{array}{l}\text { Catastrophic disasters } \\
\text { (i.e., massive destruction) }\end{array}$ & $\begin{array}{l}\text { Ecological destruction } \\
\text { (e.g., acid rain, global warming) }\end{array}$ \\
\hline Droughts & Nuclear leaks and meltdowns \\
\hline Earthquakes & Oil spills (wells and ships) \\
\hline Floods & Terrorist attacks \\
\hline Ice and hail storms & Toxic waste spills \\
\hline Insects (e.g., locusts) & Transportation accidents \\
\hline Hurricanes & (e.g., air, sea, train) \\
\hline Mudslides & War and civil destruction acts \\
\hline \multicolumn{2}{|l|}{$\begin{array}{l}\text { Secondary disasters } \\
\text { (e.g., unemployment, violence, rioting) }\end{array}$} \\
\hline \multicolumn{2}{|l|}{ Tsunami (tidal wave) } \\
\hline \multicolumn{2}{|l|}{ Typhoons } \\
\hline Volcanic Eruptions & \\
\hline
\end{tabular}


disaster professionals in psychology, identified the problems that can emerge when Western disaster professionals intervene in developing countries. Wessells writes:

In emergency situations, psychologists hired by NGOs or UN agencies often play a lead role in defining the situation, identifying the psychological dimensions of the problems, and suggesting interventions .... Viewed as experts, they tacitly carry the imprimatur of Western science and Western psychology, regarded globally as embodying the highest standards of research, education, training, and practice.... Unfortunately, the dynamics of the situation invite a tyranny of Western expertise. The multitude of problems involved usually stems not from any conspiracy or conscious intent but rather from hidden power dynamics and the tacit assumption that Western knowledge trumps local knowledge.... Local communities have specific methods and tools for healing such as rituals, ceremonies, and practices of remembrance. Since they are grounded in the beliefs, values, and traditions of the local culture, they are both culturally appropriate and more sustainable than methods brought in from the outside. (Wessells, 1999, pp. 274-275)

Lastly, no words are necessary to remind all of us of the tragic and destructive consequences of global warming. A new report notes that there has been a precipitous drop in global temperatures. The consequences are apocalyptic.

The connections - the reciprocities - that exist among these five global challenges is apparent. They feed into one another and they feed off of one another in powerful and complex ways that are becoming difficult to unravel and separate. And perhaps they should not be unraveled or separated. Perhaps we need to see them as part of global ecology that is, in fact, a totality requiring comprehension and response as such.

\section{Addressing diversity on behalf of peace and social justice \\ Actions for change}

This paper has proposed to you that problems negotiating the diversity confronting us amidst the complex global ecology of challenges we face is a major determinant of our health and well being. I have proposed that the psycho-social, socio-political, and spiritual responses to the global ecology are creating disorders that are eluding our capacity and/or willingness to resolve them. What then can we do? While the task before us is not impossible, it is difficult, and it does require, in my opinion, a spectrum of changes in attitudes, policies, and practices. Let me share some of them with you. And let me point out what we all know so well, doing any one or two of them is insufficient. They constitute a package that supports and sustains each action.

\section{(1) World citizenship}

We can no longer think of ourselves solely as citizens of various nations. Indeed, we should recognize that the very concept of establishing nations is relatively recent having emerged from the Treaties of Westphalia that brought an end to the tragic and devastating 40 years religious wars in Europe. From the Treaties of Westphalia came the modern map of European states and their subsequent imposition of the idea across other parts of the world. Today, in a global era in which corporations and other organizations are now superceding national identities and actions, we may need to consider that we are all citizens of the world. The idea is not new and found special significance after WW II as many nations sought to extricate themselves from 
the national cauldrons that had led to so much destruction. Eugene Brody (1987) quotes a 1948 World Federation for Mental Health proposal:

The question must be faced as to whether survival is possible without adapting human institutions so that people can live as world citizens in a world community, in which local loyalties are rendered compatible with a wider allegiance to mankind as a whole.... World citizenship means an informed, reflective, responsible allegiance to mankind as a whole. The movement toward world citizenship is one which fulfills, rather than goes counter to, the trend of history.... It is possible to envisage a world community built on free consent and on the respect for individual and cultural differences. (WFMH, 1948. Quoted in Brody, 1987, p. 4)

\section{(2) Universal values}

As we come to recognize and accept the virtues of the ethnocultural diversity of our world, we will need to be guided by a new set of values that are responsive to the responsibilities and requirements of life in a global era. I would like to propose the following for consideration since they implicate the major global challenges that I have cited as sources of tensions.

- Engi (Interdependency)

- Social Interest (Gemeinschaftsgefuhl)

- Inner and Outer Peace

- Diversity

- Sustainability

- Equality/Universal Human Rights

- Justice/Civility

- Education/Literacies

- Tolerance

- Spirituality/Connection/Unity

For me, these values become translated into behavior if we are willing to make the following choices. We must show, by our actions, that we choose peace over violence, freedom over oppression, voice over silence, service over self-interest, honor over advantage, cooperation over competition, action over passivity, diversity over uniformity, and justice over all.

\section{(3) A new type of leadership}

For unity and diversity to work, informed and principled global leaders are needed. I envision global leadership characterized by the following:

- A knowledge of global challenges and resources

- A prizing and prioritizing of cultural diversity

- The wisdom to inspire and guide changes with equity, ethics, and inclusion

- The character to speak for humanity rather than narrow special interests

- The ability to inspire trust, hope, and purpose

- The ability to bring people to a higher level of citizen participation and activism

- A level of intellect, erudition, and morality that recognizes the connections between and among the various global challenges we face. By this I mean the ability to understand that poverty, war, migration, environmental 
collapse do not exist as separate problems but rather as part of a complex ecology of cause and effect.

I can imagine an action agenda for global leaders of this fiber and cloth beginning with a global program that engages populations throughout the world in dialogues and discussions about the events and forces driving globalization and their consequences.

\section{(4) Attitudinal shift regarding "other"}

There is no "other". We need to embrace a new orientation that is based on connection and relationship rather than separation. Joan Halifax has stated this very clearly:

We cannot turn our backs on the tendency to turn the world and its beings into objects which we call "other." We are called more than ever to realize the obvious, that we are not, nor were we ever, living in a world of isolation. We are completely and inescapably interconnected and interdependent. (Halifax, 1999, p. i)

\section{(5) Diversity education, training, and communication competency}

Diversity education and training is clearly a worthwhile goal and activity to pursue for every society and nation in our global era. But, the righteousness of the task has not led to widespread endorsement and adoption. The struggle has been long and difficult (e.g., Marsella, 1994a). Bringing diversity training and education to schools, workplaces, and communities has been met with resistance. Far too many people see "diversity" as the source of problems and reject the call for equality as nothing more than the empowering of others at their expense. It is seen as a threat to the social formation and order and in many instances has done little to achieve diversity goals (e.g., Kalev \& Dobbin, 2006). Clearly, beliefs and values regarding "diversity" can assume the proportion of a religion with all that this implies. Thus, every effort must first be made to establish a solid foundation for developing diversity education and training.

At the heart of this foundation is the need to have people understand the nature and implications of diversity - what it is and why it is important. This will involve endorsements of diversity by major pubic figures and celebrities and guarantees that diversity is not a threat but, in fact, an opportunity for personal, societal, and national growth and change. When educational, corporate, political, and religious leaders call attention to the reality and value of diversity, a slow process of accommodation begins. This is the start.

Making people aware of their biases with respect to the many kinds of diversity can help illuminate the need for education and training, and here the issue of volunteering versus forced compliance is not be taken lightly. Indeed, forcing people to take diversity education and training can result in much resistance and countereffects.

\section{(6) Truth and reconciliation: The power of confession, apology and forgiveness}

Truth and reconciliation gained widespread public awareness following the collapse of the South African apartheid regime and the emergence of a new South African 
nation led by Nelson Mandela. In the wake of racial tensions following the changes in power, efforts were made to use a truth and reconciliation process that required perpetrators (e.g., White South African policemen) to confess their crimes of oppression (e.g., murder), to apologize, to ask forgiveness, and to state that will never occur again. However, there are a number of elements that may actually be involved including confession, apology, request for forgiveness, promise to no longer engage in behavior, and reparations. At issue, of course, are the qualities of the actions: sincerity, trust, details, and legal consequences. Truth and reconciliation can occur at many levels:

- Global

- Regional

- Nations

- Religions

- Ethnic

- Gender

- Victim Populations

- Corporations, Businesses, Organizations

- Marriages, Families

- Individuals

What is important here is the power of "apology" and the power of "forgiveness". Australia has recently experienced these powers. Diversity conflicts at all levels should consider the truth and reconciliation profess as a way of healing.

\section{(7) Universal declaration of human rights}

At the heart of the negotiating diversity for the reduction and prevention of the tensions, stresses, and threats associated with the onset and maintenance of individual, societal, and national patterns of distress and disorder, resides a document of such magnificence that it deserves a presence in every home and in every mind as a reminder of what is possible if we live according to principles of justice. That document is the United Nations' Universal Declaration of Human Rights. The UN UDHR has 30 articles. I wish to cite the first two to capture the importance and the attitude that it engenders:

On December 10, 1948 the General Assembly of the United Nations adopted and proclaimed the Universal Declaration of Human Rights. Following this historic act the Assembly called upon all Member countries to publicize the text of the Declaration and "to cause it to be disseminated, displayed, read and expounded principally in schools and other educational institutions, without distinction based on the political status of countries or territories".

Article 1: All human beings are born free and equal in dignity and rights. They are endowed with reason and conscience and should act towards one another in a spirit of brotherhood.

Article 2: Everyone is entitled to all the rights and freedoms set forth in this Declaration, without distinction of any kind, such as race, colour, sex, language, religion, political or other opinion, national or social origin, property, birth or other status. Furthermore, no distinction shall be made on the basis of the political, jurisdictional or international status of the country or territory to which a person belongs, whether it be independent, trust, non-self-governing or under any other limitation of sovereignty. 
Eloquent words on human rights have been spoken before and are usually present in most nation's constitutions. But somehow, the words of the United Nations' Declaration assume greater proportion because they are stated as universal rather than national. They speak to everyone, about everyone, and for everyone, and in doing so, they remind us of our connections and responsibilities as human beings.

\section{(8) Full-capacity global citizen}

The times in which we live require a new orientation. While past eras permitted and even encouraged us to separate our personal, professional, and civic roles and responsibilities, the global era of our times require that we merge them because of the new levels of activism and participation that are demanded from us. If we keep them separate, we may be limiting our capacity to be effective human beings in the global era. Wink Franklin (1998) has called for "... full capacity global citizens" in response to the challenges of our times. Franklin wrote:

For me there are heartwarming examples of people stepping into the role of what I call "full capacity global citizens" - people willing to take on the twin challenges of deepening their personal capacities (intuitive, spiritual, intellectual) as well as assuming responsibility for the planet and the whole of humanity.... These examples, and those from countless other groups and individuals demonstrate that we are capable of a societal vision that transcends unbridled individualism and materialism - one that is more sustainable, equitable, and multifaceted, and includes spiritual and psychological, as well as economic growth.... The shift in consciousness that seems to be required includes an accommodation of our interdependence and our need to find a basis for shared meaning and purpose. (Franklin, 1998, p. 3)

I would like to extend Franklin's noble charge by merging or fusing our personal, citizen, and professional roles and responsibilities. I say this because as we encounter the challenges of our global community, especially the issues of diversity, it is essential we encourage a new social character that chooses to be an activist in its orientation because it recognizes that our personal, citizens, and professional goals should not exist in isolation, but rather should motivate and inform us by their integration.

\section{Closing remarks}

\section{Life is diversity}

Consider this assertion: Different ethnocultural traditions represent different perceptual templates for experiencing and negotiating reality. Each opens us to a new and varied spectrum of possibilities for beliefs, values, and behaviors. Ethnocultural differences offer us choices to re-invent and re-define ourselves as individuals, societies, and nations. We can re-new ourselves again and again in different and meaningful ways not by running away from diversity, but by understanding its virtues. Life is diversity! Diversity is the very defining characteristic of life itself.

It is the diversity itself - the variations between and among everything that is alive that is the most direct and indisputable evidence that life itself seeks to encourage, promote, and sustain itself. The impulse toward life is the most powerful force in the universe - constantly seeking to adapt, adjust, and thrive amidst an infinite number of ever-changing and pressing environmental milieus. 
It is not simply human life of which I speak, but life in all of its infinite variations and the complex ecologies that exist to support life where it occurs from the tiniest blade of grass seeking to survive and grow and replicate amidst a crack in an urban sidewalk stepped on, torn, beaten back by daily pressing feet and to the most complex human societies seeking to sustain themselves amidst the presses from others and the particular environment in which they exist. In even its most rudimentary and essential forms, there is inherent in life the potential for diversity, and it is this potential which offers to life its defining capacity to respond with a variety of options and alternatives for growth and development. No living organism - plant, animal, or human - is restricted to a single monolithic form because of this potential. Life, then, is the ecological potential to respond with diverse plant, animal and cultural forms and manifestations, all of which increase the probability that life will thrive amidst different contexts. We must move beyond concern for humanity (i.e., humanism) to concern for life itself - Lifeism (Marsella, 2008).

Supporting diversity is supporting life itself, for even as life seeks to separate and distinguish itself in many forms, it constantly seeks a unity in which the parts seek a harmonious ecology. Life is animated by fission and fusion - separation and connection, isolation and relation, independence and dependence are not opposites but merely different manifestations of one nature. We must encourage and promote diversity even as we pursue unity. Can we do any less? Should not we use our capacities for reason, empathy, and compassion to rise to new levels of understanding and responsibility by responding to the diversities before us with the awe and reverence that the mystery of life deserves?

Declaration of interest: The author reports no conflicts of interest. The author alone is responsible for the content and writing of the paper.

Note

Portions of this article were presented as part of a keynote address at the International Conference on Diversity and Health, Sydney, Australia, 10 March 2008.

\section{References}

Bakan, J. (2004). The Corporation: The pathological pursuit of profit and power. New York: Free Press. Retrieved 27 February 2008 from: http://www.truthout.org/docs_2006/ 022608P.shtml

Borger, J. (2008). Feed the world: We are fighting a losing battle UN admits. The Guardian UK, Tuesday 26 February 2008.

Brody, E. (1987). Mental health and world citizenship: The view from an international nongovernmental organization. Austin, TX: Hogg Foundation for Mental Health and University of Texas. Lecture: Eric Resources information.

Chomsky, N. (2003). Hegemony or survival: America's quest for global dominance. New York: Metropolitan Books.

Franklin, W. (1998). Vision and values. Noetic Sciences Review, 44, 2-3.

Halifax, J. (1999). Foreword - Buddhist peacework: Creating cultures of peace. Somerville, MA: Wisdom Publications. 
Kalev, A., \& Dobbin, F. (2006). Best practices or best guesses? Assessing the efficacy of corporate affirmative action and diversity politics. American Sociological Review, 71, 581-617.

Krugman, P. (2008). Poverty is poison, New York Times, 18 February 2008. http:// www.nytimes.com/2008/02/18/opinion/18krugman.html?pagewanted $=$ all.

Lifton, J. (1993). The protean self: Human resilience in an age of fragmentation. New York: Basic Books.

Marsella, A.J. (1994a). Work and well being in an ethnoculturally pluralistic society: Conceptual and methodological issues. In G. Keita, \& J. Hurrell (Eds.), Job stress in a changing workforce: Investigating gender, diversity, \& family issues (pp. 147-160). Washington, DC: American Psychological Association.

Marsella, A.J. (1994b). Ethnocultural diversity and international refugees: Challenges for the global community. In A.J. Marsella, et al. (Eds.), Amidst peril and pain: The mental health and well being of the world's refugees (pp. 341-364). Washington, DC: American Psychological Association.

Marsella, A.J. (1998). Toward a global psychology: Meeting the needs of a changing world. American Psychologist, 53, 1282-1291.

Marsella, A.J. (2005). "Hegemonic" globalization and cultural diversity: The risks of global monoculturalism. Australian Mosaic, 12(4), 15-22.

Marsella, A.J. (2008). Identity: Beyond self, culture, nation, and humanity to "LIFEISM". PsySR Herald, 1May 2008, Vol. 2, \#1, pp. 1-19 (Psychologists for Social Responsibility Newsletter).

Marsella, A.J., Johnson, J., Watson, P., \& Gryczynski, J. (Eds.) (2008). Ethnocultural perspectives on disaster and trauma. New York: Springer SBM Publications.

Maser, C. (2004). The perpetual consequences of fear and violence: Rethinking the future. Washington, DC: Maisonneuve Press.

Maser, C. (2007). Culture change. 28 December 2007. Email circulation note.

Maser, C. (2008). Now we are human commodities. January 2008. CultureChange.org. Retrieved 24 February 2009 from http://www.countercurrents.org/maser020108.htm.

Pilisuk, M., \& Rountree, J. (2008). Who benefits from global violence and war: Uncovering a destructive system. Westport, CT: Praeger Security International.

Roberts, S. (2008). In a generation, minorities may be the US majority. New York Times, 14 August 2008. Available at: http://www.nytimes.com/2008/08/14/washington/ 14census.html?

Wessells, M. (1999). Culture, power and community: Intercultural approaches to psychosocial assistance and healing'. In K. Nader, N. Dubrow, \& B. Stamm (Eds.), Honoring differences. Cultural issues in the treatment of trauma and loss (pp. 267-282). Philadelphia, PA: Bruner/Mazel. 